REGARDS

SUR L'ECONOMIE ALLEMANDE

BULLETIN ECONOMIQUE DU CIRAC

\section{Regards sur l'économie allemande}

Bulletin économique du CIRAC

$91 \mid 2009$

Varia

\title{
Europe : dialogue social
}

JOBERT Annette (ed), Les nouveaux cadres du dialogue social - Europe et territoires / Dialogue social sectoriel européen : bilan et perspectives

\section{(2) OpenEdition}

Journals

Édition électronique

URL : http://journals.openedition.org/rea/3719

DOI : $10.4000 /$ rea.3719

ISBN : 978-2-8218-0878-2

ISSN : 1965-0787

Éditeur

CIRAC

Édition imprimée

Date de publication : 1 mai 2009

ISSN : 1156-8992

Référence électronique

«Europe : dialogue social », Regards sur l'économie allemande [En ligne], 91 | mai 2009, mis en ligne le 20 mai 2009, consulté le 22 septembre 2020. URL : http://journals.openedition.org/rea/3719 ; DOI : https://doi.org/10.4000/rea.3719

Ce document a été généré automatiquement le 22 septembre 2020

(C) CIRAC 


\section{Europe : dialogue social}

JOBERT Annette (ed), Les nouveaux cadres du dialogue social - Europe et territoires / Dialogue social sectoriel européen : bilan et perspectives

\section{RÉFÉRENCE}

JOBERT Annette (ed), Les nouveaux cadres du dialogue social - Europe et

territoires, P.I.E Peter Lang, Bruxelles, 2008, 267 p.

Dialogue social sectoriel européen : bilan et perspectives, Les Cahiers de la

Fondation, Europe et Société, n71-72 octobre 2008-mars 2009, 134 p.

1 La négociation collective en Europe, structurée à l'origine autour des branches professionnelles dans un cadre national, a connu depuis les années 1980 un transfert progressif vers le niveau de l'entreprise, pour s'ancrer plus récemment à l'échelon européen et territorial. Cette multiplication des espaces de dialogue social, qui s'accompagne de profondes mutations en matière de régulation, fait l'objet de l'ouvrage dirigé par A. JOBERT, sociologue et directrice de recherche au CNRS. Elle y analyse les nouveaux cadres de dialogue social sous trois angles: le dialogue social territorial, abordé d'un point de vue historique et contemporain, le dialogue social transnational dans l'entreprise, avec l'étude des comités d'entreprise européens et le dialogue social sectoriel, via l'exemple des télécommunications aux niveaux national et européen. Cette dernière approche est aussi celle choisie par Europe et Société. Son Cahier reprend ici les interventions et débats d'un colloque consacré en octobre 2008 aux comités de dialogue social sectoriel européens, institués dix ans plus tôt par la Commission et qui, par la réalité protéiforme à laquelle ils ont su donner vie, préfigurent un système de relations professionnelles au plan européen. L'objectif de ce colloque était, comme l'explique Jacques Moreau dans son éditorial, de jeter les bases « d'une réflexion pour un dialogue social authentique ", celui-ci étant un "élément essentiel pour conforter la cohésion sociale nécessaire à l'Union européenne [en réponse] aux craintes des citoyens des Etats membres ». A suivre, donc. (sh) 